\title{
ON NUMBERS AND FREEDOM
}

\section{William Gunn}

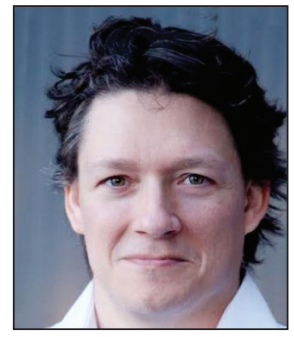

William Gunn is the Head of Academic Outreach for Mendeley, a research management tool for collaboration and discovery. He attended Tulane University as a Louisiana Board of Regents Fellow, receiving his Ph.D in Biomedical Science from the Center for Gene Therapy at Tulane University in 2008. He left academia and established the biology program at Genalyte, a novel diagnostics startup. At Mendeley, he works to make research more impactful and reproducible and is an expert on altmetrics, reproducibility, and open access.

https://orcid.org/0000-0002-3555-2054

PO Box 334, Mountain View, CA 94042, USA william.gunn@mendeley.com

\begin{abstract}
After many years of relatively slow progress, the field of research assessment and discovery has begun to change rapidly. As scholars adopt the Web for scholarly communication, more and more sources of information about research impact are becoming available, and at much greater global scale, coverage, and openness than before. This article discusses these trends, highlights the major players and ongoing work, and points to future directions.
\end{abstract}

\section{Keywords}

Impact, Metrics, Altmetrics, Trends.

\section{Título: Sobre números y libertad}

\section{Resumen}

Después de muchos años de progreso relativamente lento, el campo de la evaluación y descubrimiento de la investigación ha comenzado a cambiar rápidamente. A medida que los investigadores adoptan la Web para la comunicación científica, cada vez hay disponibles más fuentes de información sobre el impacto de la investigación, a escala global y con mucha mayor cobertura y transparencia que antes. Este artículo aborda estas tendencias, destaca los principales participantes y los trabajos en curso, y señala tendencias futuras.

\section{Palabras clave}

Impacto, Métricas, Almétricas, Tendencias.

Gunn, William (2014). "On numbers and freedom". El profesional de la información, September-October, v. 23, n. 5, pp. 463-466.

http://dx.doi.org/10.3145/epi.2014.sep.02

\section{Introduction}

Behavioral economists spend lots of time thinking about how external forces lead to collective behavior, and in psychology they frequently ask how internal forces lead to individual behavior. As the popularity of Daniel Pink's writings on motivation (Pink, 2013), Ariely's work on irrationality (Ariely, 2010), and Levitt and Dubner's Freakonomics (Dubner; Levitt, 2009) shows, the implications of these ideas are controversial, but particularly when thinking about how these ideas affect individual choice. Collectively we're ok with the idea, for example, that lower prices increase consumer demand or that advertising influences consumer choice. When that consumer happens to be you or me, well... We're far too savvy to be swayed by the attractive model in the passenger seat of the sports car ad, right? The uneasy feeling this gives us goes right to the heart of what it means to be human. Can we even say we're exercising free will if we know that we wish to do one thing yet are led to do another? Given all this, it's not surprising, therefore, that the subject of metrics and measurement of performance in research is likewise controversial, conjuring up the specter of managerialism and "efficiency optimization" in a process that depends on serendipity.

Can we even say we're exercising free will if we know that we wish to do one thing yet are led to do another? 


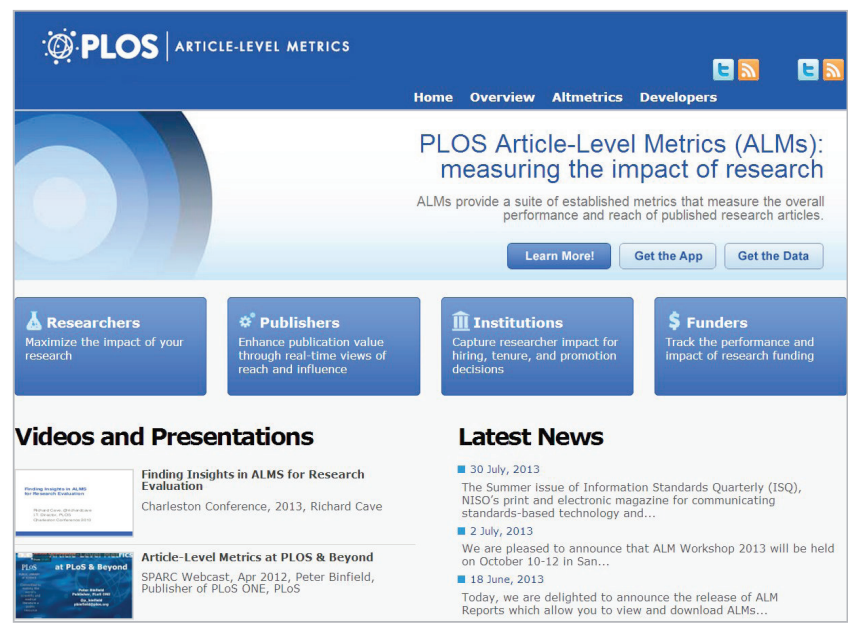

Figure 1. http://article-level-metrics.plos.org

However, sometimes the path to salvation lies through peril, because we can choose what we wish to surface. If the field of astronomy says they think an important output is the number of papers written that reference data from a specific observatory, who are funder or administrators to say otherwise? The real danger is in saying nothing and giving no guidance to those outside the field who are trying to understand if they should fund, for example, more telescopes or better means of processing the data. Fortunately, there is a group of researchers who have begun to build consensus on a range of data sources that are of relevance and the use cases where they may be applied.

\section{Impact on information professionals}

The major players currently are a group of for profit and nonprofit organizations building products in this space and researchers who have research assessment as a research interest. The Public Library of Science (figure 1), for example, has built an article-level metrics tracking tool, Impact Story (figure 2) has received a $\$ 500 \mathrm{~K}$ grant from the Sloan Foundation, Plum Analytics (figure 3) was recently acquired by Ebsco after a surprisingly short time as an independent company, and Altmetric.com has signed major deals with

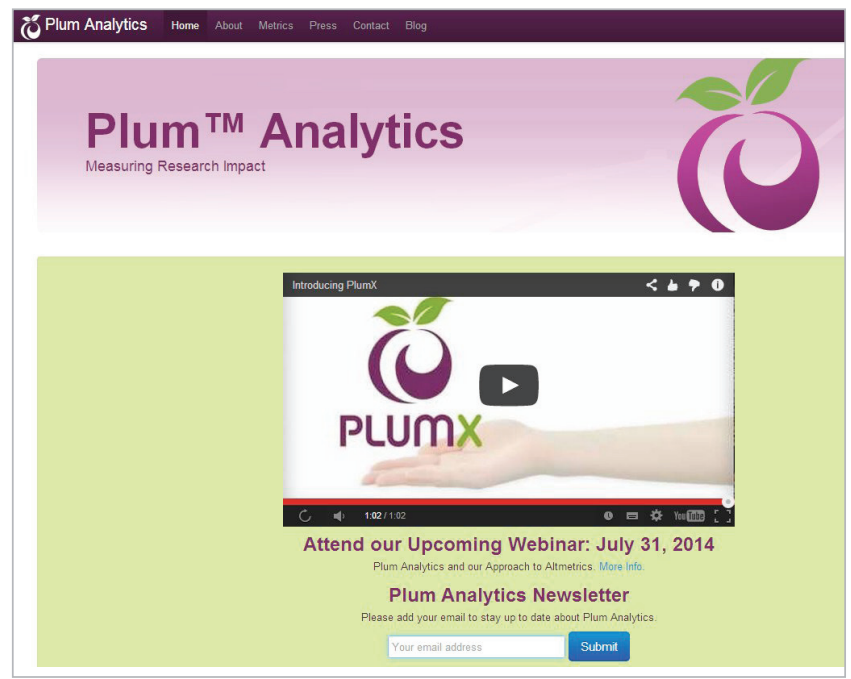

Figure 3. http://www.plumanalytics.com

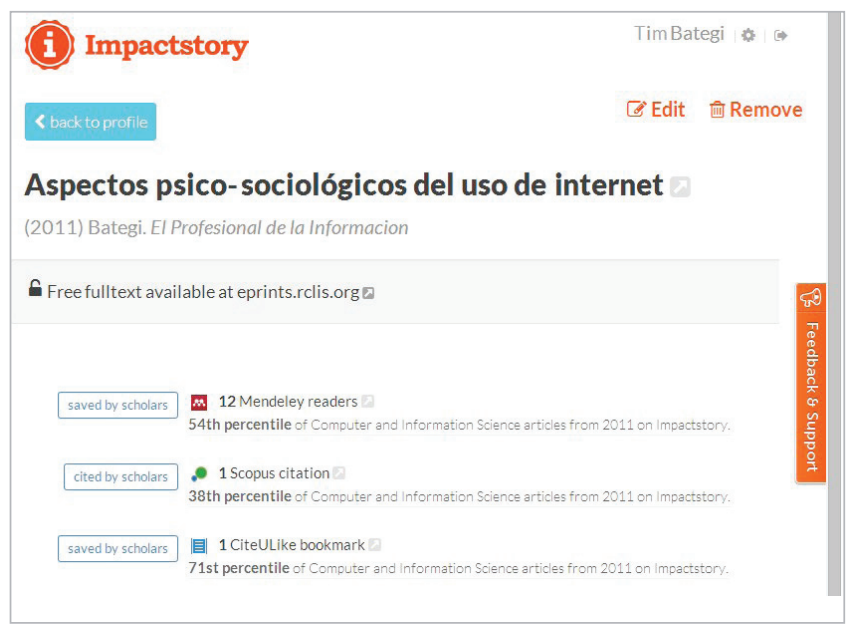

Figure 2. Example of an article's impact report https://impactstory.org

publishers such as Elsevier, Springer, and Wiley. On the academic side, there are two altmetrics conferences, one on each side of the Atlantic, and attendance is growing (figures 4 and 5). A focal point for the conversations that the two groups are having is the National Information Standards Organization, which has recently released a whitepaper resulting from a year of discussions with researchers, publishers, librarians, and funders (figure 6). Information professionals should be aware of the major players and understand how to help researchers use these new sources of data for discovery and assessment of research, as well as be able to help researchers position their articles for optimal exposure to these metrics, for example by depositing a copy of all their research outputs, including datasets and code, into the appropriate repository.

\section{The NISO altmetrics project}

In 2013, the Alfred P. Sloan Foundation awarded NISO a grant to explore emerging best practices in the area of altmetrics. NISO became interested in the work after a workshop in 2012 where a group of academics discussed incorporating signals from social media, online usage, and network analysis into a more comprehensive and useful way of discovering and assessing research, extending the previous, mostlycitation based system to encompass this richer source of signals than was accessible in the print era. After a year of discussions with various stakeholders, they published a whitepaper which outlines 25 potential areas of work, mostly dealing with the source of the metrics, the quality of the source, and the technical infrastructure necessary for integration of these metrics with existing platforms (figure 7 ).

\section{Metrics source}

The term "research output" has been adopted by the group and consists of entities such as: datasets, software, posters and presentations (grey literature), theses and dissertations, performances (film, theatre, music), non-scholarly media (blogs, newspaper articles, videos, etc.), and lectures. The importance of the concept of research output as a broader picture of a researcher's activities is underscored by the adoption of this concept into current research information systems (CRIS) and the changes made by the National 


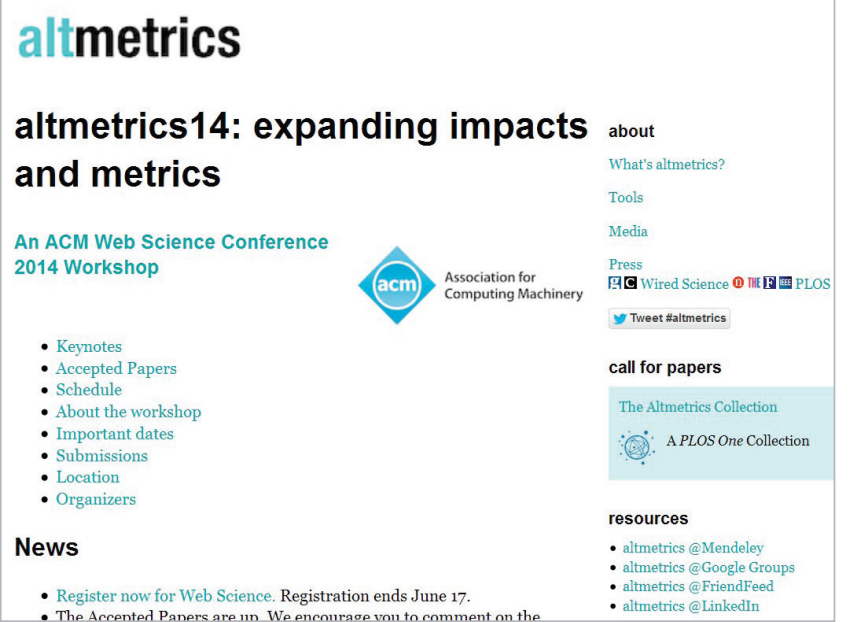

Figure 4. Altmetrics workshop at the ACM Web Science Conference 2014, Indiana University, Bloomington, USA, June $23^{\text {rd }}$ http://altmetrics.org/altmetrics14

Science Foundation (NSF 2014) and the National Institutes of Health (NIH 2014) to enable incorporation of all research outputs into a funding application biosketch.

\section{Data quality}

Data quality was highlighted as a key area of focus for NISO due to the relative newness and heterogeneity of the sources. Little is yet understood about the long-term relationship between a source and the quality of the research mentioned by the source. Additionally, online sources rise and fall more rapidly than established citation databases.

However, there are a few aspects of quality that are already apparent.

- Openness of the data is a key quality metric, promoting trust and transparency in the data, as well as enabling research and development to proceed without requiring high up-front costs or burdensome license management.

- Speed of accrual and provision of the data is another general characteristic of a high quality data source, particularly if the data is readily available for programmatic access.

- Another characteristic is the availability of provenance metadata. A key observation is that a single research object will often be covered by multiple metrics, which may provide a defense against manipulation of any one

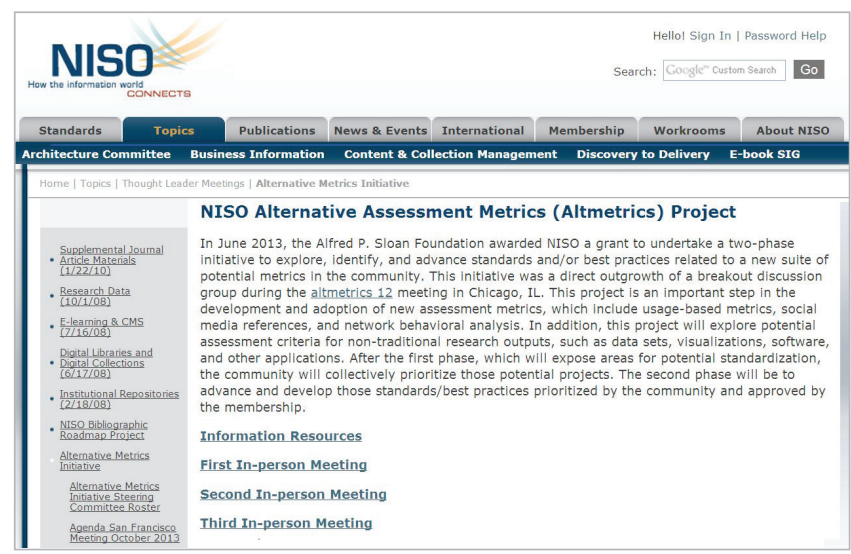

Figure 6. http://www.niso.org/topics/tl/altmetrics_initiative
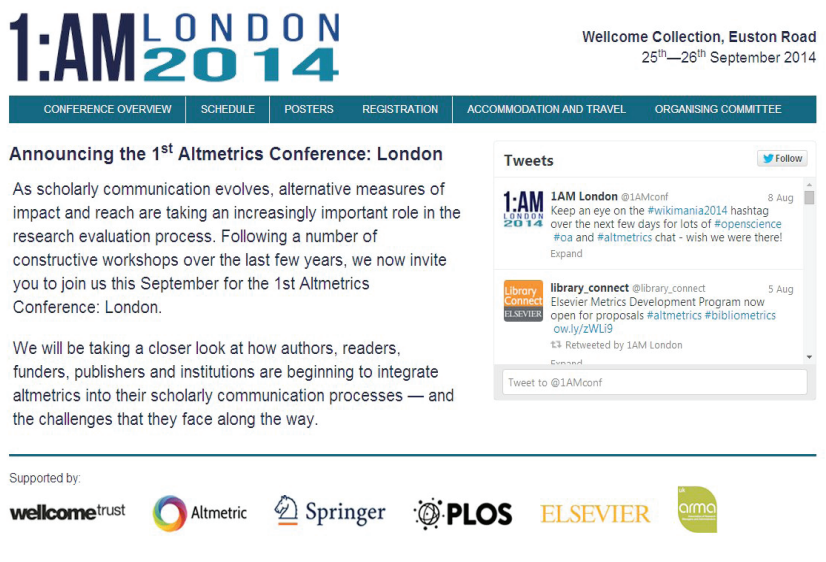

Figure 5. $1^{\text {st }}$ Almetrics Conference, London, September $25^{\text {th }}-26^{\text {th }}, 2014$ http://www.altmetricsconference.com

metric for self-aggrandizement, as well as provide useful context to the citation number. For example, if an article has hundreds of citations, but few to no readers on Mendeley, that might be an indicator of excess self-citation or citation "cartel" involvement, or it might simply come from a discipline that is underrepresented in the source examined.

Perhaps, in academia, one can be a number and a free man

\section{Use cases}

The types of use cases identified by NISO fall into two main categories: discovery and assessment.

- The discovery use case was felt to be important because increasingly discovery is computer-mediated, which means there are metrics underlying which items are retrieved in a search or presented via recommendation algorithm. The discovery use case also has more near-term impact. While use of these metrics by tenure and promotion committees still requires significant advancement in understanding and data quality, discovery or research is less critical and will likely see practical application sooner.

NISO Altmetrics Standards Project White Paper (Draft 4, June 6, 2014)

\section{Table of Contents}

Summary.

Potential Action Items

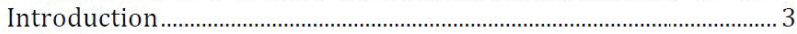

Definitions ..................................................................................................... 4

Potential Action Items.................................................................................. 5

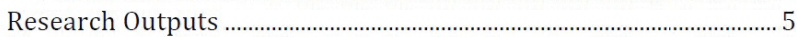

Potential Action Items.....................................................................6

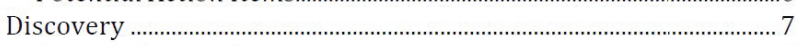

Potential Action Items..............................................................................

Research Evaluation................................................................................. 7

Potential Action Items........................................................................... 9

Data Quality and Gaming .................................................................. 9

Figure 7. http://goo.gl/PYRov1 


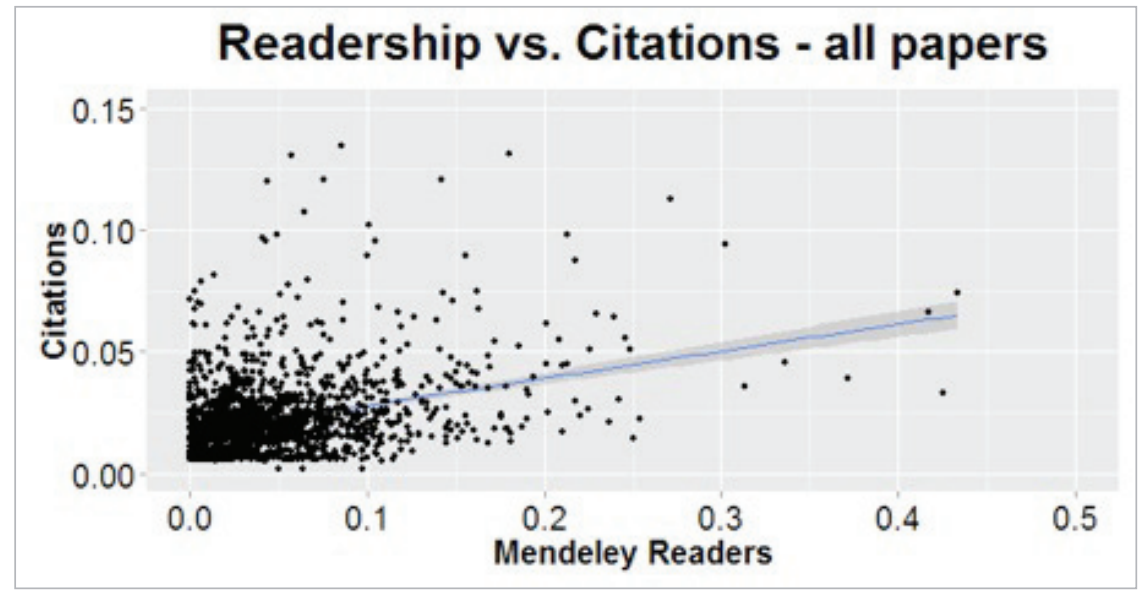

Figure 8. Normalized numbers of citations and Mendeley readers for a sample of highly-cited oncology papers published in 2010-2012 and retrieved from Scopus in 2012. Axes were truncated for display purposes. Papers above the line are more highly cited than read on Mendeley (reviews, obligatory citations, etc.), whereas papers below the line are more highly read than cited, possibly suggesting emerging impact (citations-to-be)

The general idea is that online buzz can be an early indicator of potentially high impact research, as well as the means by which collaborations may be formed more rapidly and readily. Early data from Mendeley, for example, suggests that there is some relationship between reading activity on the platform and citations (figure 8).

- The main motivation driving the adoption of altmetrics for research assessment is the need for better decision support tools. Research assessment will remain fundamentally a qualitative decision, but particularly in the Asia-Pacific region, there is a strong focus on benchmarking at the institutional level to show increasing international reputation, and thus a suite of metrics that is resistant to gaming is of considerable interest. In emerging research areas, there's also an interest in novel ways of representing impact that doesn't have the historical biases of citations and impact factor. Reduction of bias in general was seen to be a major use case for altmetrics. UK researchers should particularly take note that engagement with the social, cultural, and economic environment will make up $20 \%$ of the upcoming Research Excellence Framework (REF) and altmetrics provide a rich source of information for showing this engagement (UK HEI, 2014).

\section{Conclusion}

Each year has seen increasing numbers of developments in the field and the future of altmetrics looks very interesting. Efforts are underway to characterize the major sources of metrics and illuminate their meaning, to understand the ways in which the metrics can be manipulated for good or for ill, and to professionalize the production and collection of these metrics. This work will continue to be led by the researchers who see within altmetrics the opportunity to take back control of the process by which their research gets exposure and their work gets assessed. Perhaps, in academia, one can be a number and a free man.

\section{References}

Ariely, Dan (2010). The upside of irrationality: the unexpected benefits of defying logic. ISBN: 9780061995040 http://danariely.com

Dubner, Stephen J.; Levitt, Steven D. (2009). Freakonomics: a rogue economist explores the hidden side of everything. ISBN: 9780060731328

http://freakonomics.com

NIH (2012). Weigh in on changes to the biosketch. National Institutes of Health, June $1^{\text {st }}$.

http://nexus.od.nih.gov/all/2012/06/01/weigh-in-onchanges-to-the-biosketch

NISO (2014). NISO Alternative Assessment Metrics (Altmetrics) Project. National Information Standards Organization. http://www.niso.org/topics/tl/altmetrics_initiative

NSF (2008). Chapter II - Proposal Preparation Instructions. National Science Foundation, January $1^{\text {st }}$. http://www.nsf.gov/pubs/policydocs/pappguide/nsf08_1/gpg_2.jsp

Pink, Daniel H. (2013). To sell is human: the surprising truth about moving others. ISBN: 9781594631900 http://www.danpink.com

UK HEI (2014). Research Excellence Framework. UK higher education institutions (HEls).

http://www.ref.ac.uk

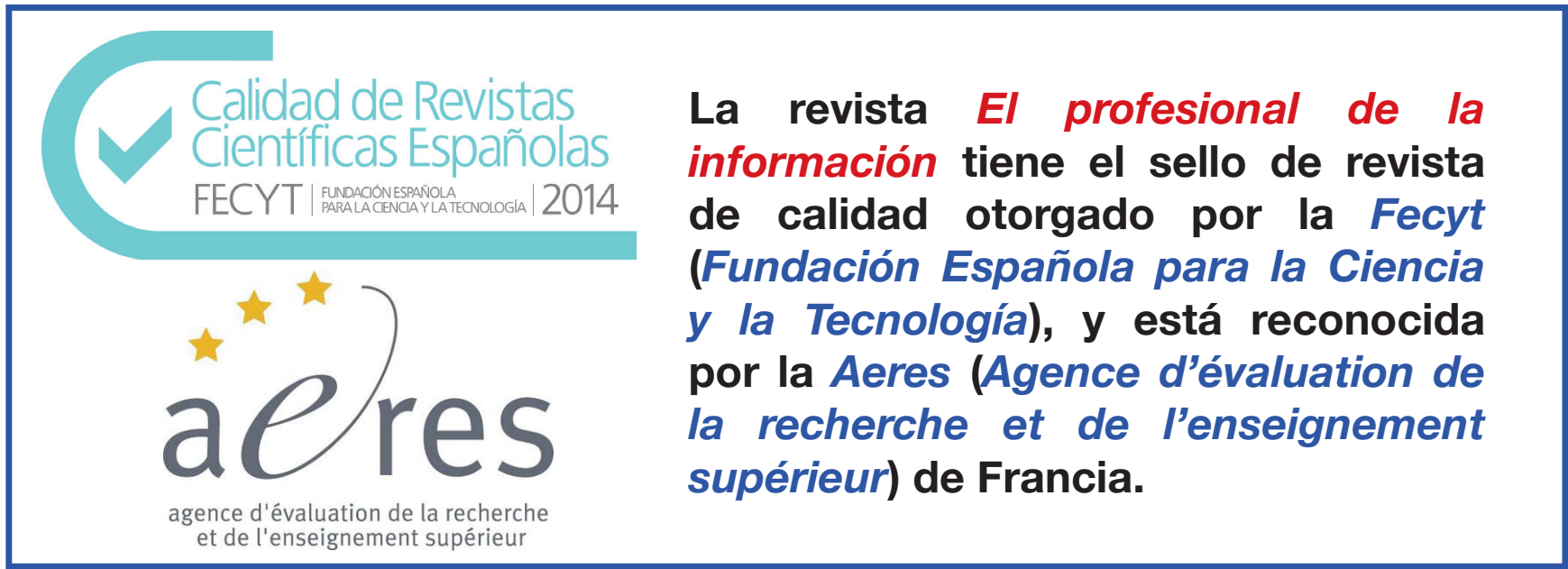

